\title{
Pengaruh Konsentrasi Asam Fosfat dalam Proses Pembuatan Karbon AKTIF SeCARa Kimia dari BaHAN BaKU KUlit SAlaK
}

\author{
THE EFFECT OF PHOSPHORIC ACID CONCENTRATION IN CHEMICALLY \\ ACTIVATED CARBON MANUFACTURING PROCESS FROM RAW MATERIAL \\ SALAK SKIN
}

\author{
${ }^{1}$ Muhammad Turmuzi, ${ }^{2}$ Halimatuddahliana, ${ }^{3}$ Orion Syaputra, ${ }^{4}$ Fatimah \\ 1,2,3,4 Departemen Teknik Kimia FT USU Medan 20155 \\ e-mail: ${ }^{1}$ turmuzi@yahoo.com, ${ }^{2}$ dahliana@yahoo.com, ${ }^{3}$ arionaritonang@gmail.com, \\ ${ }^{4}$ fatimahagussalim@yahoo.com
}

\begin{abstract}
This study aims to determine the effect of phosphoric acid concentration that impregnated in the manufacture of activated carbon from Salak skin. Materials used include Salak skin from South Tapanuli district. The variables were observed are activated carbon yield and iodine. In this study, the dried Salak skin is refined to 1-2 $\mathrm{mm}$ in size. Then the Salak skin impregnated with phosphoric acid at a concentration of $10 \%, 15 \%$, and $20 \%$ for 3 hours at a temperature of $85^{\circ} \mathrm{C}$. After that, it is filtered and dried for 24 hours at temperature of $60^{\circ} \mathrm{C}$ in an oven. Then it is pyrolyzed using a temperature of $500^{\circ} \mathrm{C}$ for 3 hours. The results show the highest yield is at a temperature of $500{ }^{\circ} \mathrm{C}$ for 2 hours with a concentration of $20 \%$ that is $68 \%$. The highest iodine is at a temperature of $500^{\circ} \mathrm{C}$ in concentration of $20 \%$ with a time of 3 hours pyrolysis that is $888 \mathrm{mg} / \mathrm{g}$.
\end{abstract}

Keywords: activated carbon, Salak skin, iodine, yield

\begin{abstract}
Abstrak. Penelitian ini bertujuan untuk mengetahui pengaruh konsentrasi asam fosfat yang diimpreganasi dalam pembuatan karbon aktif dari kulit salak. Bahan yang digunakan antara lain kulit salak yang diperoleh dari Kabupaten Tapanuli Selatan. Variabel-variabel yang diamati antara lain yield karbon aktif dan bilangan iodin. Pada penelitian ini, kulit salak yang telah dikeringkan dihaluskan ukurannya menjadi 1-2 mm. Kemudian kulit salak diimpregnasi dengan asam fosfat dengan konsentrasi $10 \%$, 15\%, dan 20\% selama 3 jam pada suhu $85^{\circ} \mathrm{C}$. Setelah itu disaring dan dikeringkan selama 24 jam pada suhu $60{ }^{\circ} \mathrm{C}$ di dalam oven. Setelah itu dipirolisis dengan menggunakan suhu $500{ }^{\circ} \mathrm{C}$ selama 3 jam. Hasil penelitian menunjukkan yield tertinggi berada pada suhu $500{ }^{\circ} \mathrm{C}$ selama 2 jam dengan konsentrasi $20 \%$ yaitu sebesar 68\%. Bilangan iodin tertinggi berada pada suhu 500 ${ }^{\circ} \mathrm{C}$ pada konsentrasi $20 \%$ dengan waktu pirolisis 3 jam yaitu $888 \mathrm{mg} / \mathrm{g}$.
\end{abstract}

Kata kunci: karbon aktif, kulit salak, bilangan iodin, yield

\section{Pendahuluan}

Karbon aktif selalu digunakan dalam industri seperti untuk pemisahan, penyimpanan dan pemurnian gas, hal ini wajar kerana karbon aktif mempunyai kapasitas penyerapan yang tinggi dan kinetika penyerapan yang tinggi terutama untuk gas. Struktur pori karbon aktif tergantung pada bahan baku dan kaedah pengaktifan. Pada dasarnya untuk menghasilkan karbon aktif teridiri dari proses fisika dan kimia. Pengaktifan fisika dilakukan dua langkah, yaitu pirolisis bahan baku dan dilanjut dengan pengaktifan dengan gas pengoksida seperti uap dan karbon dioksida pada suhu tinggi. Sedangkan pengaktifan kimia hanya dalam satu langkah yaitu mencampur bahan kimia dengan bahan baku untuk selanjutnya dipirolisis. 
Selain proses pembuatan karbon aktif, jenis bahan baku sangat berperan dalam menghasilkan karbon aktif. Pada dasarnya semua bahan berkarbon yang alami dan bersifat tidak melebur dan tidak lembut dapat dipertimbangkan sebagai bahan baku karbon. Selain itu syarat penting lain yang perlu dipenuhi adalah kandungan zat volatile rendah, unsur karbon harus tinggi dan kekuatan stress yang memadai (Janskowa, et al. 1991). Untuk memperoleh karbon aktif dengan biaya yang rendah, maka para peneliti terdahulu banyak mengarahkan penelitian sebagai sumber bahan baku terhadap limbah pertanian seperti tempurung buah walnat, biji zaitun (Rodriguez-Reinoso \& MolinoSabio 1992, Gonzalez et al. 1997), tempurung kacang Macadamia (Nguyen\& Do 1995), tempurung kelapa sawit (Hussein, et al. 1996 dan tempurung kelapa (Laine \& Yunes 1992). Kulit salak mengandung lignosellulosa sehingga ada kemungkinan dapat dijadikan sebagai salah satu bahan baku pembuatan karbon aktif. Pada kajian ini limbah kulit salak dijadikan sebagai bahan baku proses pembuatan karbon aktif dengan proses kimia $\mathrm{H}_{3} \mathrm{PO}_{4}$.

\section{Metode Penelitian}

Bahan baku kulit salak diperoleh dari limbah industri salak di Desa Parsalakan Kecamatan Angkola Barat Tapanuli Selatan. Kajian ini dilakukan dalam dua tahap yaitu impregnasi asam fosfat dan dilanjutkan dengan pirolisis (Yakout et al. 2012). Impregnasi diawali dengan pencacahan kulit salak sehingga diperoleh ukuran 1-2 mm. Kulit salak direndam dalam larutan asam fosfat 10, 15 dan $20 \%$, diaduk pada suhu $85^{\circ} \mathrm{C}$ selama 3 jam. Kulit salak yang telah diimpregnasi dipisahkan dengan cairan asam fosfat dengan penyaringan. Selanjutnya dikeringkan pada suhu $60^{\circ} \mathrm{C}$ selama 24 jam. Kulit salak yang telah kering dimasukkan ke dalam furnace vertikal, suhu dinaikkan dengan laju $8{ }^{\circ} \mathrm{C} /$ menit sampai suhu mencapai $400{ }^{\circ} \mathrm{C}$ selama 2 jam. Selama proses pirolisis, furnace dialiri gas $\mathrm{N}_{2}$ dengan laju $100 \mathrm{ml} /$ menit. Setelah suhu mencapai suhu ruangan, sampel dicuci dengan akuades sehingga dicapai $\mathrm{pH}$ netral. Sampel yang telah dicuci dikeringkan pada suhu $105^{\circ} \mathrm{C}$ dan selanjutnya disimpan dalam desikator. Karakterisasi karbon aktif dilakukan dengan menggunakan Bilangan Iodin. Bilangan iodin adalah teknik yang digunakan untuk menentukan kapasitas adsorpsi karbon aktif. Bilangan iodin dapat digunakan sebagai pendekatan untuk luas permukaan dan mikropori karbon aktif dengan presisi yang baik (Srisa-Ard, 2014). Penyerapan iodin dengan karbon aktif brehubungan dengan karakteristik porositas terhadap pengukuran tingkat aksebilitasnya pada molekul. Bilangan iodin telah ditentukan dalam mg/g. Pada penelitian ini, sebanyak 0,5 gram karbon aktif ditimbang. Kemudian dicampur dengan iodin $0,1 \mathrm{~N}$ sebanyak $25 \mathrm{~mL}$ dan diaduk selama 15 menit. Setelah itu dilakukan penyaringan dan diukur sebanyak $10 \mathrm{~mL}$. Hasil dari penyaringan sebanyak $10 \mathrm{~mL}$ dititrasi dengan natriumtiosulfat $0,1 \mathrm{~N}$ hingga berwarna kuning gading. Setelah itu ditambahkan indikator amilum 1\% sebanyak 3 tetes dan ditirasi kembali natrium tiosulfat hingga berwarna bening. Bilangan iodin dapat dihitung dengan persamaan :

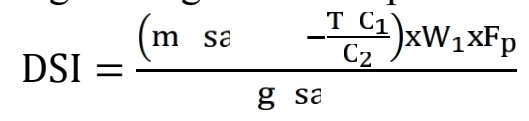

Keterangan;

$\begin{array}{ll}\mathrm{DSI} & =\text { Daya serap iodin }(\mathrm{mg} / \mathrm{g}) \\ \mathrm{mL} \text { sampel } & =\text { filtrat yang dititrasi }(10 \mathrm{~mL}) \\ \mathrm{T} & =\text { Volume titrasi } \mathrm{Na}_{2} \mathrm{SO}_{3} \mathrm{~N} \\ \mathrm{C}_{1} & =\text { Konsentrasi } \mathrm{Na}_{2} \mathrm{SO}_{3} \mathrm{~N} \\ \mathrm{C}_{2} & =\text { Konsentrasi iod }(\mathrm{N}) \\ \mathrm{W}_{1} & =\text { Berat iod }(12,69 \mathrm{mg} / \mathrm{L})\end{array}$


$\mathrm{Fp} \quad=$ faktor pengenceran

\section{Hasil dan Pembahasan}

\subsection{Hasil (Yield) Karbon Aktif}

Yield karbon aktif merupakan parameter dalam pirolisis (Mohammad et al., 2008). Yield karbon aktif dapat dihitung dengan menggunakan persamaan:

$Y=\frac{M_{1}}{M_{2}} x 100 \%$

Keterangan;

$$
\begin{aligned}
& \mathrm{Y}=\text { yield karbon aktif } \\
& \mathrm{M}_{1}=\text { massa karbon aktif } \\
& \mathrm{M}_{2}=\text { massa sampel kering tanpa aktivator }
\end{aligned}
$$

Pengaruh suhu terhadap persentase yield karbon aktif yang dihasilkan dapat dilihat pada Gambar 1.

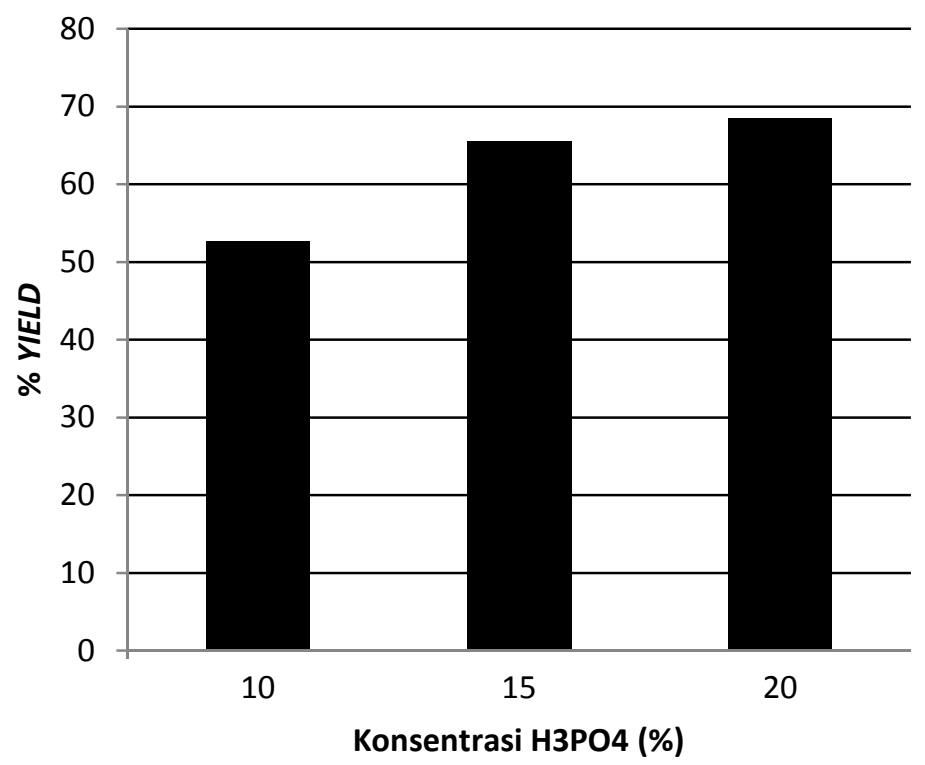

Gambar 1. Pengaruh Konsentrasi Asam Fosfat Terhadap Yield pada Suhu $500^{\circ} \mathrm{C}$ dan waktu 3 jam

Semakin tinggi konsentrasi maka yield yang dihasilkan semakin besar. Hal ini dapat dijelaskan dengan reaksi oksidasi bahan organik yang dapat terjadi dalam lingkungan oksigen dan jumlah asam fosfat yang cukup untuk melakukan perannya dalam menyilangkan rantai karbon dan akibatnya kerangka karbon pada prekursor terlindung dari oksidasi (Sahu, et al. 2010). Pertambahan konsentrasi asam, reaksi kondensasi senyawa aromatik yang dapat menyebabkan pengurangan produk gas dari struktur hidroaromatik pada karbonisasi char sehingga meningkatkan yield pada karbon (Mohammad, 2008).

\subsection{Bilangan Iodin}

Salah satu cara untuk melihat besarnya struktur pori karbon aktif adalah menggunakan bilangan iodin. Bilangan iodin merupakan parameter dasar yang paling penting yang digunakan untuk karakterisasi karbon aktif. Berdasarkan standar kualitas 
arang aktif menurut SNI penetapan daya serap arang aktif terhadap iodium merupakan persyaratan umum untuk menilai kualitas arang aktif yang bertujuan untuk mengetahui kemampuan arang aktif untuk menyerap zat dengan ukuran molekul yang lebih kecil. Semakin besar angka iod yang dihasilkan maka semakin besar kemampuan dalam mengadsorpsi. Pengaruh konsentrasi asam fosfat terhdap bilangan iodin dapat dilihat pada Gambar 2.

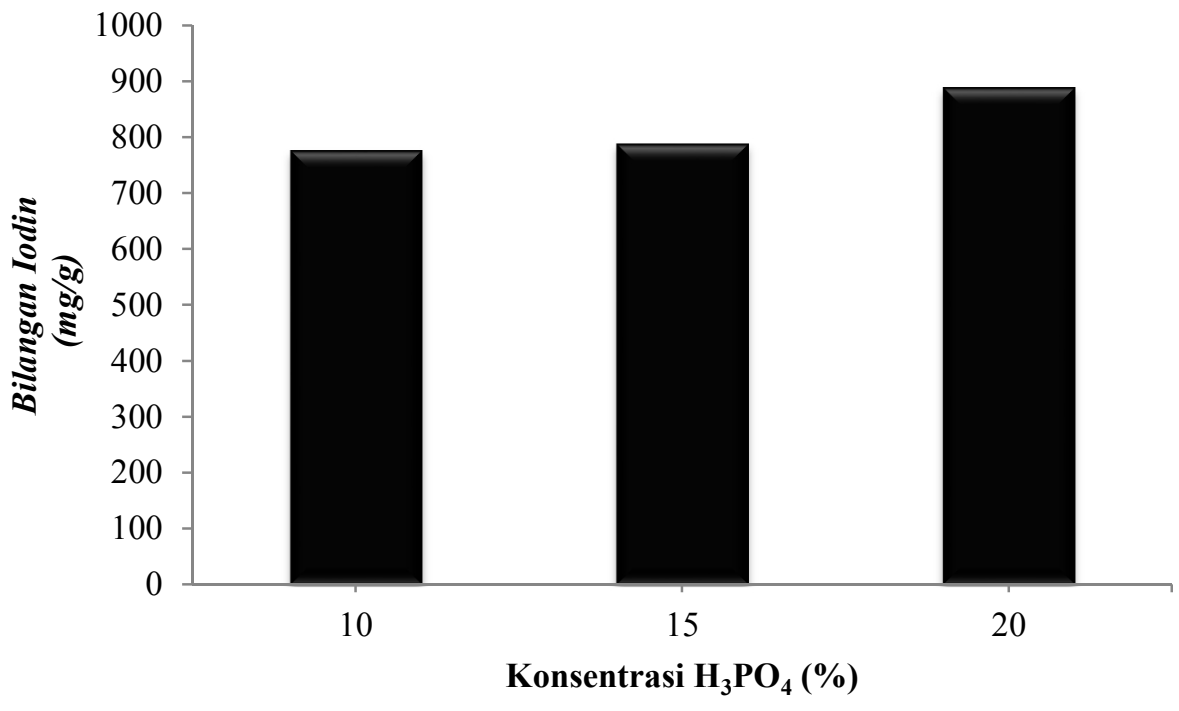

Gambar 2. Pengaruh Konsentrasi $\mathrm{H} 3 \mathrm{PO} 4$ terhadap Bilangan Iodin pada Suhu $500^{\circ} \mathrm{C}$ dan waktu 3 jam

Semakin besar konsentrasi asam fosfat ada kecenderungan semakin besar bilangan iodin. Bahan aktivasi bertindak sebagai katalis asam/basa dalam pembelahan ikatan, hidrolisis, dehidrasi dan kondensasi, disertai dengan reaksi cross-linking antara asam/alkali dan biopolimer (Sugumaran, et al., 2012). Reaksi pada lignoselulosa dengan asam fosfat dimulai pada saat pencampuran. Asam fosfat pertama menyerang hemiselulosa dan lignin, karena selulosa lebih resisten pada hidrolisis asam. Penambahan aktivator memberikan pengaruh yang kuat untuk mengikat senyawasenyawa tar keluar melewati pori-pori dari karbon aktif sehingga permukaan dari karbon aktif tersebut semakin lebar atau luas yang menyebabkan semakin besar pula daya serap karbon aktifnya (Suhendarwati et al. 2012). Dari hasil percobaan yang telah dilakukan diperoleh bahwa dayaserap iodine paling besar terdapat pada temperatu 500 ${ }^{\circ} \mathrm{C}$ pada konsentrasi $\mathrm{H}_{3} \mathrm{PO}_{4} 20 \%$ sebesar $888 \mathrm{mg} / \mathrm{g}$.

\section{Kesimpulan dan Saran}

Berdasarkan hasil kajian diatas dapat disimpulkan bahwa semakin besar konsentrasi $\mathrm{H}_{3} \mathrm{PO}_{4}$ akan menghasilkan yield yang lebih besar. Struktur pori semakin berkembang dengan semakin besar konsentrasi $\mathrm{H}_{3} \mathrm{PO}_{4}$.

Untuk penelitian lebih lanjut perlu dilakukan penelitian struktur karbon aktif dengan analisa BET dan SEM. 


\section{Daftar pustaka}

Badan Pusat Statistik. 'Pertanian dan Industri' http://www.bps.go.id diunduh pada tanggal 25 Desember 2014

Gonzalez, M.T., Rodriguez-Reinoso, F., Garcia, A.N. \& Marcilla, A. 1997. $\mathrm{CO}_{2}$ activation of olive stones carbonized under different experimental conditions. Carbon 35(1): 159-165.

Hussein, M.Z., Tarmizi, R.S.H, Zainal, Z. \& Ibrahim, R. 1996. Preparation and characterization of active carbons from ail palm shell. Carbon 34(11): 1447-1454.

Jankowska, H., Swiatkowski, A. \& Choma, J. 1991. Active Carbon. New York: Ellis Horwood.

Laine, J. \& Yunes, S. 1992. Effect of the preparation method on the pore size distribution of activated carbon from coconut shell. Carbon 30(4): 601-604

Mohammad, Rafie R., Itimad I. Taha dan Arwa M. Othman. Preparation Of Phosphorized Granular Activated Carbon From Beji Asphalt Using Concentrated $\mathrm{H}_{3} \mathrm{PO}_{4}$ Tikrit Journal of Pure Science Vol. 13 No.(3) 2008

Nguyen, C. \& Do, D.D. 1995. Preparation of carbon molecular sieves from Macadamia nut shells. Carbon 33(12): 1717-1725

Rodriguez-Reinoso, F. \& Molino-Sabio, M. 1992. Activated carbon from lignocellulosic materials by chemical and/or physical activation: an overview. Carbon 30(7): 1111-1118.

Sahu, J.N., Acharya, J., Meikap, B.C . Optimization of production conditions foractivated carbons from Tamarind wood by zinc chloride using response surface methodology. Bioresour. Technol. 101, 2010 : hal. 1974-1982.

Srisa-Ard, Samarn. 2014. "Preparation of Activated Carbon from Sindora Siamensis Seed and Canarium Sublatum Guillaumin fruit for Methylene Blue Adsorption". International Transaction Journal of Engineering, Management, \& Applied Sciences \& Technologies. ISSN 2228-9860. Volume 5 No.4 : 235-245

Sugumaran P, V. Priya Susan2, P. Ravichandran and S. Seshadri. "Production and Characterization of Activated Carbon from Banana Empty Fruit Bunch and Delonix regia Fruit Pod". Journal of Sustainable Energy \& Environment 3 (2012). hal 125132

Suhendarwati. Lina, Bambang Suharto, dan Liliya Dewi Susanawati. Pengaruh Konsentrasi Larutan Kalium Hidroksida pada Abu Dasar Ampas Tebu Teraktivasi. Jurnal Sumberdaya Alam \& Lingkungan 2012 Vol. 19

Yakout. S.M, G. Sharaf El-Deen. 2012. Characterization of activated carbon prepared by phosphoric acid activation of olive stones. Arabian Journal of Chemistry. 70 